\title{
Kırşehir İlindeki Arılıklarda Nosema Hastalığının Belirlenmesi
}

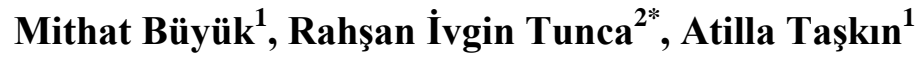 \\ ${ }^{I}$ Ahi Evran Üniversitesi, Ziraat Fakültesi, Zootekni Bölümü, 40100 Kırşehir, Türkiye \\ ${ }^{2}$ Muğla Sttkı Koçman Üniversitesi, Ula Ali Koçman Meslek Yüksek Okulu, Bitkisel ve Hayvansal Üretim Bölümü, 48640 Muğla, Türkiye
}

M A K A L E B İ L G İ S İ

Araştırma Makalesi

Geliş 06 Nisan 2016

Kabul 20 Ocak 2017

Anahtar Kelimeler:

Apis mellifera L.,

Nosema ceranae

Nosema apis

Kurşehir

Türkiye

*Sorumlu Yazar:

E-mail: rivgin@gmail.com
Ö Z

Bu çalışmada ergin bal arılarında Nosema ceranae ve Nosema apis sporlarının neden olduğu Nosema hastalığının Kırşehir ilinde bulunan kolonilerde varlığı ve dağılımının belirlenmesi amaçlanmıştır. Çalışmada, Kırşehir ilinin 5 ilçesindeki (Merkez, Mucur, Akpınar, Boztepe ve Kaman), 31 lokasyonda bulunan 51 arılıktan 2014 yılında her arılığg temsilen 100 ergin işçi arı örneği olmak üzere toplam 5100 arı örneği araştırılmıştır. Çalışmada yapılan mikroskobik incelemelerde Merkez ilçede \%25, Mucur ilçesinde $\% 23,07$, Akpınar ilçesinde \%12,5, Boztepe ilçesinde \%60 nosema sporu varlı̆̆1 tespit edilirken Kaman ilçesindeki arılıklarda hastalığa rastlanılmamıştır. Nispi nem ve Nosema spor sayıları arasında pozitif korelasyon $(\mathrm{r}=0,708)$ tespit edilmiştir. Moleküler karakterizasyon yapılan nosema sporu pozitif örneklerin tümünde hastalık etkeninin $N$. ceranae olduğu tespit edilmiştir.

Turkish Journal Of Agriculture - Food Science And Technology, 5(1): 1-5, 2017

Determination of Nosema Disease in Colonies of Kırşehir Province

\section{A R T I C L E IN F O}

\section{Research Article}

Received 06 April 2016

Accepted 20 January 2017

Keywords:

Apis mellifera $\mathrm{L}$.

Nosema ceranae

Nosema apis

Kırşehir

Turkey

\section{*Corresponding Author:}

E-mail: rivgin@gmail.com

\section{A B S T R A C T} \begin{abstract}
The aim of the study was to determine the prevalence of Nosema disease caused by Nosema ceranae and Nosema apis in bee colonies in Kırşehir. A hundred worker honey bee samples were collected from each of 51 beekeepers in 31 locations in 5 provinces of Kırşehir (Centrium, Mucur, Akpınar, Boztepe and Kaman) in July 2014. A total 5100 samples were used in this study. The microscopic examinations of the study suggested that there was existence of Nosema spores in Centrium, Mucur, Akpınar and Boztepe with $25 \%, 23.07 \%, 12.5 \%$ and $60 \%$, respectively; whereas no spores were detected in Kaman province. It was found a positive correlation between humidity and numbers of nosema spores. Molecular analyses showed that $N$. ceranae is only Nosema type in studied all positive samples.
\end{abstract}

\section{Giriş}

Ülkemiz, 10.000'in üzerinde doğal çiçekli bitki türü ile dünyadaki önemli gen merkezlerinden biridir (Kence, 2006). Aynı zamanda değişik bölgelere adapte olmuş arı 1rk ve ekotiplerini barındırmaktadır (Karadeniz, 2012). Anadolu'daki zengin bitki örtüsü ve iklim koşulları sayesinde hemen hemen her bölgede ve her mevsimde arıcılık faaliyetleri yürütülmektedir (Sıralı, 2009; Yoloğlu, 2014). Bu kadar iklimsel ve bölgesel avantaja rağmen, ülkemiz arıcılık faaliyetleri sonrasında elde edilen arı ürünler istatistiksel verilere göre ekonomik anlamda istenilen düzeyde bulunmamaktadır. (Kaygın ve Yıldız, 2006). Yapılan araştırmalar koloni yönetiminde verimi artırmaya yönelik yeni düzenlemeler yapılmasının gerekliliğine işaret etmektedir (Muz ve ark., 2012; Büyük ve ark., 2014; Anonim, 2014).

Arıcılık faaliyetlerini kısıtlayan nedenler arasında arı hastalık ve zararlıları ön sıralarda yer almaktadır (Rangberg ve ark., 2012). Nosema önemli ar1 hastalıklarından biridir ve ergin balarılarında oldukça yaygın görülen Microsprodia grubunda yer alan Nosema cinsi içinde bulunan Nosema apis ve Nosema ceranae türleri bu hastalığa neden olmaktadır (Ütük ve ark., 2010; Whitaker ve ark., 2010; Büyük ve ark., 2014). Nosema hastalığı etkenlerinden biri olan N. apis sporlarını 1909 yılında Enoch Zander, bal arılarında orta bağırsak epitelyumunda tespit ederek sınıflandırmıştır (Webster ve ark., 2004; Higes ve ark., 2010). 
Önceleri Nosema hastalığına neden olan etkenin sadece $N$. apis olduğu ve dünyanın her yerine yayıldığı düşünülmekteydi (Somerville ve Hornitzky, 2007; Higes ve ark., 2010; Büyük ve ark. 2014). Ancak, Fries ve ark., (1996) N.ceranae'nın Asya bal arısını (Apis ceranae) enfekte eden bir patojen olduğunu tespit etmișlerdir. Daha sonraki yıllarda yapılan çalışmalarda ise N.ceranae'nın Avrupa bal arısını da (A. mellifera L.) enfekte ettiği bir çok çalışma ile bildirilmiştir (Chen ve ark., 2009; Higes ve ark., 2006; Huang ve ark., 2007; Tosun, 2012). N.ceranae' nın yavaş yavaş N.apis'in yerini aldığ 1 belirtilmektedir (Higes, 2006; Chen ve ark. 2008, 2009; Williams ve ark. 2008, 2014; Ütük ve Ark., 2010; Fries, 2010; Staron ve ark., 2012). Son yıllardaki çalışmalar, N.ceranae'nın Taiwan, tüm Avrupa, Kuzey Amerika ve Avusturalya'ya kadar yayılım gösterdiğini ortaya koymaktadır (Higes ve ark., 2006; Huang ve ark., 2007; Whithaker ve ark., 2010).

$\mathrm{Bu}$ çalıșmada, son yıllarda dünya genelinde de koloni kayıplarına neden olduğu düşünülen $N$. apis ve $N$. ceranae kaynaklı nosema hastalığının, Kırşehir ilinin 5 farklı ilçesindeki arılıklardan alınan bal arısı örneklerinde moleküler ve mikroskobik tanımlama ile dağılımı ve yoğunluğu araştırılmıştır.

\section{Materyal ve Yöntem}

Çalışmada Kırşehir iline ait 5 ilçeden (Merkez, Mucur, Kaman, Akpınar ve Boztepe) 31 köy ve 51 arılıktan 2014 yılının Temmuz ayı süresince örnekler toplanmıştır (Tablo 1). Arı örnekleri toplanırken nosemaya karşı ilaçlama yapılmamış arılıklardan örnekler alınmıştır. Her arılığı temsilen arılık başına 100 tarlacı işçi arı toplanarak toplam 5100 bal arısı örneğiyle çalışılmıştır. Nosema düzeyinin belirlenmesi için hazırlanan homojenatlar için World Organization for Animal Health (OIE) Uygulama kılavuzunun (2008) belirtmiş olduğu yöntem kullanılmıştır. Hazırlanan homojenatlarda ki nosema spor sayımları hemositometre üzerinde 400x büyütmeli 1șı mikroskobunda gerçekleştirilmiştir (OIE, 2008).

Nosema sporu düzeyi tespit edilmiş örneklerde ve Etlik Veteriner Kontrol Merkez Araştırma Enstitüsü'nden temin edilmiş pozitif örneklerde ticari DNA izolasyon kiti (Fermantas K512) kullanılarak DNA izolasyonu gerçekleştirilmiştir. PZR toplam reaksiyon hacmi $10 \mu \mathrm{l}$. olacak şekilde; $1 \mu \mathrm{l}$ DNA, 0,5 U. Taq DNA Polimeraz, 10X PCR Buffer, $3 \mathrm{mM} \mathrm{MgCl} 2,0,3 \mathrm{mMdNTP}, 0,4 \mu \mathrm{M}$ 218MITOC FOR ve REV, 0,5 $\mu \mathrm{M}$ 321APIS FOR ve 321APIS REV primerleri ve $\mathrm{H}_{2} \mathrm{O}$ kullanılarak hazırlanmıştır.

Tablo 1 Arılık sayıları ve bulunduğu köylerin koordinatları

\begin{tabular}{|c|c|c|c|c|}
\hline & Yerleşim Yeri & Arılık Sayıs1 & Örnek Say1s1 & Yerleşim Yeri Koordinatları \\
\hline \multirow[t]{8}{*}{ Kurşehir } & Sevdiğin & 1 & 100 & $39^{\circ} 7^{\prime} 16.00^{\prime \prime K} 34^{\circ} 2^{\prime} 4.34^{\prime \prime D}$ \\
\hline & Tatarilyasyayla & 1 & 100 & $39^{\circ} 27^{\prime} 39.01^{\prime \prime K} 34^{\circ} 5^{\prime} 58.89^{\prime \prime D}$ \\
\hline & Dulkadirli & 3 & 300 & $39^{\circ} 30^{\prime} 40.26^{\prime \prime} \mathrm{K} 34^{\circ} 9^{\prime} 52.08^{\prime \prime} \mathrm{D}$ \\
\hline & Seyrekköy & 2 & 200 & $39^{\circ} 26^{\prime} 42.80^{\prime \prime K} 34^{\circ} 16^{\prime} 21.04^{\prime \prime D}$ \\
\hline & Kervansaray & 1 & 100 & $39^{\circ} 9^{\prime} 37.11^{\prime \prime K} 34^{\circ} 10^{\prime} 33.00^{\prime \prime} \mathrm{D}$ \\
\hline & Dinekbağ & 3 & 300 & $39^{\circ} 7^{\prime} 7.17 " \mathrm{~K} 34^{\circ} 8^{\prime} 55.13 " \mathrm{D}$ \\
\hline & Özbağ & 3 & 300 & $39^{\circ} 12^{\prime} 45.20^{\prime \prime} \mathrm{K} 34^{\circ} 8^{\prime} 29.68^{\prime \prime} \mathrm{D}$ \\
\hline & Kindam & 2 & 200 & $39^{\circ} 7^{\prime} 52.47^{\prime \prime K} 34^{\circ} 11^{\prime} 52.82^{\prime \prime D}$ \\
\hline \multirow[t]{11}{*}{ Mucur } & Şatıroğlu & 1 & 100 & $39^{\circ} 5^{\prime} 48.48^{\prime \prime} \mathrm{K} 34^{\circ} 23^{\prime} 18.67^{\prime \prime} \mathrm{D}$ \\
\hline & Altınyazı & 1 & 100 & $41^{\circ} 4^{\prime} 17.88^{\prime \prime K} 26^{\circ} 34^{\prime} 34.27^{\prime \prime} \mathrm{D}$ \\
\hline & Asmakaradam & 1 & 100 & $38^{\circ} 59^{\prime} 35.45^{\prime \prime K} 34^{\circ} 27^{\prime} 29.18^{\prime \prime D}$ \\
\hline & Budak & 2 & 200 & $39^{\circ} 8^{\prime} 17.50^{\prime \prime K} 34^{\circ} 27^{\prime} 24.53^{\prime \prime} \mathrm{D}$ \\
\hline & Kurugöl & 1 & 100 & $39^{\circ} 2^{\prime} 53.50^{\prime \prime} \mathrm{K} 34^{\circ} 26^{\prime} 5.16^{\prime \prime} \mathrm{D}$ \\
\hline & Kuşaklı & 1 & 100 & $39^{\circ} 17^{\prime} 26.98^{\prime \prime K} 34^{\circ} 36^{\prime} 16.27^{\prime \prime D}$ \\
\hline & P1narkaya & 1 & 100 & $38^{\circ} 58^{\prime} 32.46^{\prime \prime K} 34^{\circ} 25^{\prime} 35.33^{\prime \prime D}$ \\
\hline & Yazıkınık & 2 & 200 & $39^{\circ} 9^{\prime} 6.96^{\prime \prime K} 34^{\circ} 24^{\prime} 37.63^{\prime \prime D}$ \\
\hline & Kilıçlı & 1 & 100 & $39^{\circ} 16^{\prime} 2.33^{\prime \prime K} 34^{\circ} 40^{\prime} 47.21^{\prime \prime D}$ \\
\hline & Tataryeğenağa & 1 & 100 & $39^{\circ} 2^{\prime} 43.67^{\prime \prime K} 34^{\circ} 35^{\prime} 4.86^{\prime \prime D}$ \\
\hline & Gümüşkümbet & 1 & 100 & $39^{\circ} 10^{\prime} 20.22^{\prime \prime K} 34^{\circ} 19^{\prime} 50.56^{\prime \prime D}$ \\
\hline \multirow[t]{4}{*}{ Boztepe } & Çimeli & 1 & 100 & $39^{\circ} 17^{\prime} 36.63^{\prime \prime K} 34^{\circ} 12^{\prime} 46.71^{\prime \prime D}$ \\
\hline & Hatunoğlu & 1 & 100 & $39^{\circ} 24^{\prime} 37.08^{\prime \prime K} 34^{\circ} 21^{\prime} 40.91^{\prime \prime D}$ \\
\hline & Karacaören & 2 & 200 & $39^{\circ} 13^{\prime} 23.42^{\prime \prime} \mathrm{K} 34^{\circ} 15^{\prime} 44.46^{\prime \prime} \mathrm{D}$ \\
\hline & Boztepe- Merkez & 1 & 100 & $39^{\circ} 16^{\prime} 21.81^{\prime \prime K} 34^{\circ} 15^{\prime} 53.49^{\prime \prime} \mathrm{D}$ \\
\hline \multirow[t]{4}{*}{ Akpinar } & Pekmezci & 2 & 200 & $39^{\circ} 30^{\prime} 9.54^{\prime \prime K} 34^{\circ} 2^{\prime} 23.65^{\prime \prime D}$ \\
\hline & Boyalık & 2 & 200 & $39^{\circ} 30^{\prime} 27.91^{\prime \prime K} 33^{\circ} 59^{\prime} 54.33^{\prime \prime D}$ \\
\hline & Çalıburnu & 1 & 100 & $39^{\circ} 29^{\prime} 44.05^{\prime \prime K} 33^{\circ} 51^{\prime} 25.93^{\prime \prime D}$ \\
\hline & Çiftliksarıkaya & 3 & 300 & $39^{\circ} 23^{\prime} 33.06^{\prime \prime K} 34^{\circ} 0^{\prime} 57.39^{\prime \prime D}$ \\
\hline \multirow[t]{4}{*}{ Kaman } & Demirli & 3 & 300 & $39^{\circ} 17^{\prime} 56.22^{\prime \prime} \mathrm{K} 33^{\circ} 56^{\prime} 40.43^{\prime \prime D}$ \\
\hline & Başköy & 3 & 300 & $39^{\circ} 20^{\prime} 14.82^{\prime \prime K} 33^{\circ} 50^{\prime} 50.25^{\prime \prime D}$ \\
\hline & İmancilı & 1 & 100 & $39^{\circ} 24^{\prime} 22.23^{\prime \prime K} 33^{\circ} 52^{\prime} 34.21^{\prime \prime D}$ \\
\hline & Ömerhacılı & 2 & 200 & $39^{\circ} 17^{\prime} 50.35^{\prime \prime K} 33^{\circ} 49^{\prime} 16.86^{\prime \prime D}$ \\
\hline Toplam & Yerleşim yeri: 31 & 51 & 5100 & \\
\hline
\end{tabular}


PZR koșulları, $94^{\circ} \mathrm{C}^{\prime} \mathrm{de} 15$ sn, $61,8^{\circ} \mathrm{C}^{\prime}$ de 30 sn. $72^{\circ} \mathrm{C}$ 'de 45 sn. 10 döngü ve $94^{\circ} \mathrm{C}$ 'de 15 sn. $61,8^{\circ} \mathrm{C}^{\prime}$ de 30 sn. $72^{\circ} \mathrm{C}^{\prime}$ de 50 sn. 20 döngü ve son döngüyü takiben $72^{\circ} \mathrm{C}$ 'de 5 dk. son uzama işlemi yapılarak gerçekleştirilmiştir. PZR ürünleri \%1,2' likagaroz jelde yürütülmüş, EthBr. ile boyanıp, UV altında görüntülenmiştir. Hissedilen sıcaklık, Nisbi nem ve Nosema sporları için ortalama standart hata $\left(\bar{X} \pm S_{\bar{x}}\right)$ belirlenmiştir. Hissedilen sıcaklık, nisbi nem ve Nosema spor sayıları arasındaki ilişkiyi göstermek için korelasyon katsayıları (r) hesaplanmıştır.

\section{Bulgular}

$\mathrm{Bu}$ çalışmada Kırşehir ilinde Merkez, Akpınar, Boztepe, Kaman ve Mucur ilçelerindeki arılıklarda nosemeosis varlığı araştırılmıştır ve Kırşehir genelindeki arılıkların \%21,56'sında nosema sporlarına rastlanmıştır. İlçelere göre dağılımı ise; Kırşehir merkezinde 16 arılığın 4' ünde (\%25), Akpınar ilçesinde 8 arılıktan 1' inde $(\% 12,5)$, Boztepe ilçesinde 5 arılıktan 3'ünde (\%60), Mucur ilçesinde 13 arılıktan 3' ünde $(\% 23,07)$ Nosema varlığ arılıklarda nosema sporlarına rastlanılmamıştır.

Meteoroloji İl Müdürlüğünden alınan Kırşehir ili 2014 yılına Temmuz ayına ait sicaklık, nisbi nem ve nosema sporları için ortalama ve standart hatalar $\left(\bar{X} \pm S_{\bar{x}}\right)$ Tablo 2 'de gösterilmiştir. Meteorolojik verilerine göre nisbi nem oranı en yüksek Akpınar ilçesinde tespit edilmiştir (\%48). İlçeden alınan örneklerde nosema sporu ile bulaşıklık düzeyi $\% 12,5$ ve spor sayısı ortalamaları $13,10^{4}$ olarak tespit edilmiştir. Diğer yandan en düşük nisbi nem ortalamaları Kırşehir merkez ilçede tespit edilmiştir $(\% 38,4)$. Ortalama spor sayıs $21,10^{4}$ olarak belirlenirken nosema bulaşıklık düzeyi \%25 olarak belirlenmiştir. Nosema bulaşıklık düzeyi en yüksek tespit edilen Boztepe ilçesinden alınan örneklerde ortalama spor sayısı $24,10^{4}$ olarak belirlenmiştir. Bu ilçe için ölçülmüş nisbi nem $(\% 42,97)$ ve hissedilen ortalama sicaklık $\left(22,88^{\circ} \mathrm{C}\right)$ iken en fazla nosema varlığı (\%60) bu ilçede belirlenmiştir. Ortalama spor sayısı en yüksek Mucur ilçesinden alınan örneklerde belirlenmiştir $\left(41.10^{4}\right)$. Mucur ilçesi için nisbi nem ortalamaları \%43,33 olarak belirlenmiştir. Bu değer Akpınar'dan ilçesinden sonra ölçülen en yüksek ikinci değerdir. Diğer yandan Mucur ilçesi 2014 yılı Temmuz ayı için ortalama sıcaklık $24,3^{\circ} \mathrm{C}$ belirlenmiş ve Merkez ilçeden sonra ikinci yüksek sıcaklığın gözlemlendiği bölgedir. Sicaklık, nispi nem verileri ve nosema spor sayıları arasındaki doğrusal ilişkiler (korelasyon katsayıları=r) hesaplanmıştır. Nisbi nem ve nosema spor sayıları arasındaki doğrusal ilişki $\mathrm{r}=0,708^{*}$ olarak bulunmuştur. Nosema spor yoğunluğu ile nem arasındaki doğrusal ilişki istatistiksel olarak önemlidir $(\mathrm{P}<0,05)$ (Tablo 3).

Mikroskobik ön değerlendirme ile nosema spor bakımından bulaşık olan örneklerde ve Etlik Veteriner Kontrol Merkez Araştırma Enstitüsü'nden temin edilen N.apis ve N.ceranae pozitif örneklerde DNA izolasyonunun ardından multipleks PZR işlemi gerçekleştirilmiştir. Analiz sonucunda tüm pozitif örneklerde gözlemlenen sporun $N$. ceranae olduğu tespit edilmiştir (Resim 1).

Tablo 2 Örnek toplanan beş bölge için sporları tanımlayıcı istatistik sonuçları

\begin{tabular}{l|ccccc}
\hline \multicolumn{1}{c|}{ Bölgeler } & $\begin{array}{c}\text { Spor Sayıs } \\
\text { Ortalamalar }\end{array}$ & $\mathrm{N}$ & $S_{\bar{x}}$ & $\begin{array}{c}\text { Hissedilen sicaklık } \\
\text { Ortalamalar1 }\left({ }^{\circ} \mathrm{C}\right)\end{array}$ & $\begin{array}{c}\text { Nisbi nem } \\
\text { Ortalamaları }(\%)\end{array}$ \\
\hline Merkez & $21,10^{4}$ & 4 & 42526 & 25,51 & 38,38 \\
Mucur & $41,10^{4}$ & 3 & 159117 & 24,31 & 43,33 \\
Boztepe & $24,10^{4}$ & 3 & 91866 & 22,88 & 42,97 \\
Akpınar & $13,10^{4}$ & 1 & - & 23,81 & 48,00 \\
Kaman & 0 & 0 & 0 & 23,82 & 41,55 \\
\hline
\end{tabular}

Tablo 3 Nosema sporlarının sıcaklık ve nem arasındaki korelasyon değerleri

\begin{tabular}{l|cc}
\hline \multicolumn{1}{c|}{ Ortam Koşulları } & Spor Sayısı & Hissedilen sıcaklık Ortalamaları \\
\hline Hissedilen sıcaklık Ortalamaları & $-0,180$ & \\
Nisbi nem Ortalamaları & $0,708^{*}$ & $-0,719^{*}$ \\
\hline
\end{tabular}

$* \mathrm{P}<0,05$ önem seviyesinde istatistiksel olarak önemlidir.

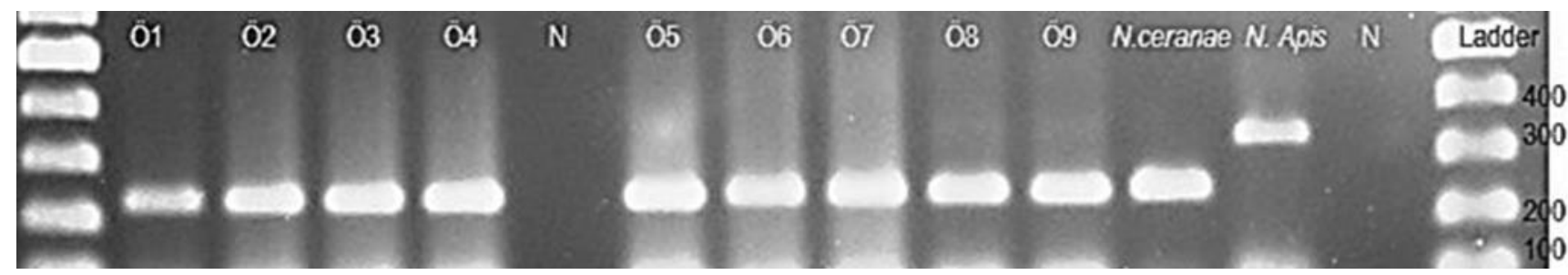

Resim 1 Multiplex PZR sonrası agaroz jel görüntüsü

(Ö1- Ö9:Numuneler; N: Negatif PZR ürünü; N. ceranae ve N. Apis: Pozitif örnek) 


\section{Tartışma ve Sonuç}

Ülkemizde 1952 yılından bu yana nosema hastalı̆̆ının varlığı bilim adamları tarafindan farklı zaman ve bölgelerde ortaya konmuştur. Bilim adamları tarafından gerçekleştirilen çalışmalarda kullanılan farklı yöntem ve teknikler $N$. apis ve $N$. ceranae' ya konukçusu olan bal arılarının (Apis mellifera L.) çeşitli vücut kısımlarında rastlanabileceğini göstermiştir (Somerville ve Hornitzky, 2007; Chen ve ark., 2009). Bu çalışma sırasında toplanan örneklerde Boztepe ilçesindeki arılıklarda \%60 seviyesinde nosema sporlarına rastlanmıştır. Nosema sporlarının sayılarının yüksek olmasının ve bulaşıklık düzeyinin bu bölge için yüksek çıkmasının nedeni bölgeye gelen diğer arılıkların hastalık etmenini taşıması ve bölge arıcılarla olan arı alışverişiyle alakalı olabileceği görüşünü doğurmuştur. Diğer yandan ortak su kaynaklarının kullanımı yine bölgede hastalık etmeninin bulaşmasında etkenler arasında yer alabileceği ön görülmektedir. Kaman ilçesinden alınan örneklerde hastalık etmenine rastlanmamıştır. Ülkemizde yapılan bazı çalışmalarda zaman zaman yapılan örneklemelerde nosema hastalığına rastlanmayabilmektedir. Şahinler ve Gül'ün (2005) yaptığı çalışmada Hatay yöresinde 11 ilçe ve 51 köyde çeşitli arı hastalık ve zararlılarının incelenmiş 5730 kolonide nosema hastalığına rastlanmadığı belirtilmiştir (Şahinler ve Gül, 2005). Yoloğlu (2014) 12 ilden örnek toplanmış ve Mersin, Kırklareli, Edirne, Sivas, İzmir illerinden toplanan örneklerden nosema sporlarına rastlanılmadığ

Ülkemizde birçok çalışma yapılarak nosema hastalığının varlığı çeşitli illerde tespit edilmiştir. Kutlu (1988) Adana ve Muğla illerinde, Başar (1990) Muğla ve İstanbul, Aydın (2001) Çanakkale, Balıkesir ve Bursa illerinde, Çakmak ve ark. (2003) Bursa Bölgesinde, Topçu ve Arslan (2004), Kars ili ve ilçelerinde, Şimşek (2005) Elazı̆̆ yöresinde, Soysal ve Gürcan (2005) Tekirdağ yöresinde, Gül ve Kutlu (2009)'da Bingöl ve çevresinde nosema hastalığının varlığını belirlemişlerdir. Kırşehir ilinde Nosema hastalığının varlığı ilk kez Tunca ve Çimrin'in (2012) 118 arıcı ile yapmış olduğu anket çalışmasında hastalığın arılıklarda $\% 5,1$ seviyesinde olduğu bildirilmiştir. Mevcut çalışmada örnek toplanan 51 arılıkta nosema varlığının \%21,56 olduğu görülmüştür. Anket çalışmasında belirtilen hastalığın varlığının daha düşük seviyede görülmesinin nedenlerinin başında elde edilen verilerin arıcının hastalığın semptomlarını gözlemleyerek verdikleri yanıtlara göre elde edilmesidir. Diğer yandan, iklim koşullarının o y1l ki değerleri (Sıcaklık ve nisbi nem gibi), arıcıların hastalık hakkında yeterli tecrübe ve gözleme sahip olmamaları, hastalığın gözle görülür belirtilerinin ancak hastalığın ilerleyen dönemlerinde ortaya çıkmasıyla gözlem yapılabilmesini zorlaştırmakta ve nosema sebebiyle olan kayıpların nedeninin tam olarak anlaşılamaması olabilir.

Ülkemizde Nosema hastalığının tür içi tayinleri moleküler tekniklerin kullanılmasıyla 2010 yılından bu yana yapılabilmektedir. Ütük ve ark., (2010) Samsun ve Giresun illerinde, Muz ve ark. (2010), Hatay ve Güney Marmara bölgesinde, Tosun (2012) Artvin, Rize, Trabzon, Giresun, Ordu, Gümüşhane ve Bayburt illerinde, Yoloğlu (2014), Ardahan, Hakkâri, Mersin, Muğla, Kırklareli, Yalova, Edirne, Sivas, Artvin, Balıkesir, İzmir,
Niğde illerinde, Yaman ve ark. (2015) Ordu bölgesinde nosema etkenlerinin tür tayinlerini yapmışlardır. Yapılan bu çalışmalarda $N$. cerana ve $N$. apis varlığına rastlandığı bildirilmiştir.

$\mathrm{Bu}$ çalışmada nosema sporları rastlanmış örneklerden elde edilen DNA analizi sonucunda rastlanılan nosema patojeninin alt türü $N$. ceranae olarak belirlenmiştir. Çalışmada nem değerinin sıcaklığa nazaran daha etkili bir faktör olduğu belirlenmiş ve yapılan istatistiksel analizler sonucunda kovan başına düşen spor sayısındaki artış ile nem düzeyindeki artış arasında önemli ilişki olduğu ortaya konmuştur. Türkiye'de Özgör ve ark. (2015) Isparta, Artvin ve Burdur illerinden alınan örneklerde yapılan çalışma $N$. ceranae düzeyinin nemle birlikte arttığ 1 bildirilmiştir.

Yapılan bu çalışmada, nem, sıcaklık ve spor sayılarındaki doğrusal ilişkiyi analizi ile ilgili olarak elde edilen bulgular daha önceden yapılmış olan çalışmaları desteklemektedir (Tosun, 2012;Gisder ve ark., 2010; Martin- Hernandez ve ark., 2009).

Sonuç olarak, ergin bal arılarında etkili olan nosema hastalığının Kırşehir genelindeki arılıklarda \% 21.56 oranında tespit edilmiştir. Kovan başına verimin artırılması için arı hastalık ve zararlılarıyla mücadele, bakım besleme konularında gerekli eğitimlerin verilmesi gerekmektedir. Kovanların doğru bakımı ve yönetimi birçok hastalığın önlenmesinin temelini oluşturacağından hastalıkların nasıl tedavi edileceğinden ziyade koruyucu önlemlere öncelik verilmelidir.

\section{Teşekkür}

Arı örneklerinin sağlayan tüm arıcılarımıza, Olgay Kaan TEKİN'e, $N$. cerana ve $N$. apis pozitif örneklerin sağlandığ 1 Veteriner Kontrol Merkez Araştırma Enstitüsüne teşekkür ederiz. Bu makale Mithat BÜYÜK' ün Yüksek Lisans Tezinden oluşturulmuştur. Yazarlar arasında çıkar çatışması bulunmamaktadır.

\section{Kaynaklar}

Anonim. 2014. Erişim Adresi: http://faostat.fao.org/site/339/ default.aspx (Erişim: 10.11.2015)

Aydın L, Güleğen E, Çetinbaş H. 2001. Prevalence of Nosema apis in Southern Marmara Region in Turkey. Apimondia. ISBN: 0-620-27768-8.

Başar E. 1990. Ülkemizdeki Bal Arılarında (Apis mellifera) Acarapis Woodi ve Nosema apis Parazitlerinin Araştırılması. Yüksek Lisans Tezi, Hacettepe Üniversitesi, Ankara.

Büyük M, Tunca Rİ, Taşkın A. 2014. Türkiye'de Nosema spp. Varlığına Yönelik Yapılmış Çalışmalar. Türk Tarım ve Doğa Bilimleri Dergisi. 1(2): 234-238.

Chen Y, Evans JD, Smith IB, Pettis JS. 2008. Nosema ceranae is a Long-Present and Wide-Spread Microsporidian İnection of The European HoneyBee (Apis mellifera) in The United States. Journal of Invertebrate Pathology. 97: 186-188.

Chen YP, Evans JD, Murphy C, Gutell R, Zuker M, GundensenRindal DAWN, Pettis JS. 2009. Morphological, molecular, and phylogenetic characterization of Nosema ceranae, a microsporidian parasite isolated from the European honeybee, Apis mellifera. Journal of Eukaryotic Microbiology, 56(2): 142-147. 
Çakmak İ, Aydın L, Güleğen AE. 2003. Güney Marmara Bölgesinde Balarısı Zararlıları Ve Hastalıkları. Uludağ Arıcılık Dergisi. 1: 33-35.

Fries I, Feng F, Da Silva A, Slemenda SB, Pieniazek NJ. 1996. Nosema ceranae Sp. (Microspora, Nosematidae), Morphological and Molecular Characterization of a Microsporidian Parasite of The Asian Honey Bee Apis cerana. (Hymenoptera, Apidae) European Journal of Protistology. 32: 356-365.

Fries I. 2010. Nosema ceranae in European honeybees (Apis mellifera). Journal of İnvertebrate Pathology. 103: 73-S79.

Higes M, Martín-Hernández R, Meana A. 2006. Nosema ceranae, a New Microsporidian Parasite in Honeybees in Europe. Journal of Invertebrate Pathology. 92: 93-95.

Higes M, Martín-Hernández R, Meana A. 2010. Nosema ceranae in Europe: an EmergentType $\mathrm{C}$ Nosemosis. Apidologie. 41(10) 37-53.

Huang WF, Jiang JH, Chen YW, Wang CH. 2007. A Nosema ceranae isolate from the honeybee Apis mellifera. Apidologie. 38(1): 30-37.

Karadeniz T. 2012. Meyve Yetiştiriciliğinde Polinasyonun Önemi, Verim ve Kaliteye Etkisi. 3. Uluslararası Muğla Arıcılık ve Çam Balı Kongresi, Bildiri Kitabı. 275-282.

Kaygın AT, Yıldız Y. 2006. Bartın Yöresi Bal Arısı (Apis mellifera L.) (Hymenoptera, Apidae) Zararlıları. ZKÜ Bartın Orman Fakültesi Dergisi. 8-10.

Kence A. 2006. Türkiye Balarılarında Genetik Çeşitlilik ve Korunmasının Önemi. Uludağ Arıcılık Dergisi. Şubat, 2532.

Kutlu MA. 1988. Ergin Balarısı (Apis mellifera L.) Hastalı̆̆ Nosemaapis'in Dağılımı ve Enfeksiyon Oranı Üzerine Bir Araştırma. Yüksek Lisans Tezi, Çukurova Üniversitesi, Fen Bilimleri Enstitüsü. Adana.

Muz MN, Solmaz H, Yaman M, Karakavuk M. 2012. Kış Salkımı Erken Bozulan Arı Kolonilerinde Paraziter ve Bakteriyel Patojenler. Y.Y.U. Veteriner Fakültesi Dergisi, 23 (3): 147-150.

Özgör E, Güzerin E, Keskin N. 2015. Determinatinand Comparision of Nosema apis and Nosema ceranae in Terms of Geographic and Climatic Factors. Hacettepe Journal of Biology and Chemistry. 43 (1): 9-15.

Rangberg A, Diep DB, Rudi K, Amdam GV. 2012. Paratransgenesis: an Approach to Improve Colony Health and Molecular Insight in Honey Bees (Apis mellifera). Integrative and Comparative Biology. 52 (1): 89-99.

Sıralı R. 2009. Türkiye'nin Önemli Bal Üretim Bölgeleri. Arıcılık Araştırma Dergisi. 1: 16-20.

Staron M, Jurovcikova J, Cermakova T, Staronova D. 2012. A Scientific Note on Incidence of Nosema apis and Nosema ceranae in Slovakia During The Years 2009 and 2010, Slovak Journal of Animal Science. 1(45): 36-38.
Somerville D, Hornitzky M. 2007. Nosema disease. Erişim: http://www.dpi.nsw.gov.au/_data/assets/pdf_file/0003/177 519/nosema-disease.pdf (Erişim Tarihi: 27.10.20015).

Soysal Mİ, Gürcan EK. 2005. Tekirdağ İli Arı Yetiştiriciliği Üzerine Bir Araştırma. Tekirdağ Ziraat Fakültesi Dergisi. 2: 161-165.

Şahinler N, Gül A. 2005. Hatay Yöresinde Bulunan Arıcılık İşletmelerinde Arı Hastalıklarının Araştırılması. Uludag Bee Journal February. 5: 27-31.

Şimşek H. 2005. Elazığ Yöresi Bal Arılarında Bazı Parazit ve Mantar Hastalıklarının Araştırılması. Ankara Üniversitesi, Veterinerlik Fakültesi Dergisi. 52: 123-126.

Topçu B, Arslan MÖ. 2004. Kars Yöresindeki Balarılarında Nosemosis'in Yaygınlığı. Uludağ Arıcılık Dergisi. 4: 164170.

Tosun O. 2012. Bal Arılarında (ApisMellifera L., 1758) Nosemosis (Nosematosis) Hastalığının Doğu Karadeniz Bölgesinde Bulunan Arı Kolonilerindeki Varlığı, Dağılımı Ve Hastalık Etkenlerinin Karakterizasyonu. Doktora Tezi, 112 sayfa, Karadeniz Teknik Üniversitesi, Fen Bilimleri Enstitüsü, Biyoloji Anabilim Dalı, Trabzon.

Tunca Rİ, Çimrin T. 2012. Kırșehir İlinde Bal Arısı Yetiştiricilik Aktiviteleri Üzerine Anket Çalışması. Iğdır Üniversitesi, Fen Bilimleri Ensitüsü Dergisi. 2: 99-108.

Ütük AE, Pişkin FÇ, Kurt M. 2010. Türkiye'de Nosema ceranae' nın İlk Moleküler Tanısı. Ankara Üniversitesi Veterinerlik Fakültesi Dergisi. 57: 275-278.

Yoloğlu, N. 2014. Türkiye'deki Bal Arılarında Görülen Nosemosis Üzerine Bir Çalıșma. Yüksek Lisans Tezi, 34 sayfa, Ordu Üniversitesi, Fen Bilimleri Enstitüsü, Ordu.

Whitaker J, Szalanski AL, Kence M. 2010. Molecular Detection of $N$. ceranae and $N$. apis From Turkish Honey Bees. Apidologie. 42(2): 174-180.

Williams GR, Shafer ABA, Rogers REL, Shutler D, Stewart DT. 2008. First Detection of Nosema ceranae, a Microsporidian Parasite of European Honey Bees (Apis mellifera), in Canada and Central USA. Journal of Invertebrate Pathology. 97: 189-192.

Williams GR, Shutler D, Burgher-MacLellan KL, Rogers REL. 2014. Infra Population and Community Dynamics of The Parasites Nosema apis and Nosema ceranae, and Consequences for HoneyBee (Apis Mellifera) Hosts. Published. Erișim: http://journals.plos.org/plosone/ article?id=10.1371/journal.pone.0099465, (Erişim: 15.11.2015).

Webster TC, Pomper KW, Hunt G, Thacker EM, Jones SC. 2004. Nosema apis İnfection in Worker and Queen Apis mellifera. Apidologie. 35: 49-54.

Yaman M, Yarılgaç EŞ, Güner BG, Ertürk Ö. 2015. Ordu Yöresi Bal Arılarında Nosemosis Hastalığının Varlığı Ve Dağılımı. Türkiye Parazitoloji Dergisi. 39: 47-51. 